\title{
Enough of the 'Snake Oil': Applying a Business and Human Rights Lens to the Sexual and Reproductive Wellness Industry
}

\author{
Clare Patton $^{1 *}$ (D), Marisa McVey ${ }^{2}$ and Ciara Hackett ${ }^{3}$ \\ ${ }^{1}$ Lecturer, School of Law, Queen's University Belfast, UK \\ ${ }^{2}$ Postdoctoral Research Fellow at St Andrew's School of Management and Aston Law School, \\ Birmingham, UK \\ ${ }^{3}$ Senior Lecturer, School of Law, Queen's University Belfast, UK \\ *Corresponding author. Email: c.patton@qub.ac.uk
}

\begin{abstract}
The female sexual and reproductive wellness industry is flourishing, valued at around US\$4.5trn globally. Heavily focused on the female reproductive life cycle, products are marketed to women and girls from puberty through to the menopausal years, with medically unsubstantiated claims that can fail to deliver on promises made and leave damaging physical and psychological side-effects. In this article we ask: do the harms caused by the sexual and reproductive wellness industry fall within the boundaries of business and human rights (BHR) scholarship? We establish the landscape of the industry, identify human rights relating to sexual and reproductive healthcare and education, and use BHR literature to make the case that the industry should be placed on the BHR research agenda so that the various tools used in BHR such as the law, corporate governance, and the weight of public consciousness, can be applied to encourage appropriate regulation of this industry.
\end{abstract}

Keywords: advertising; marketing; right to health and education; sexual and reproductive health; sexual and reproductive wellness industry

\section{Introduction}

This article examines the highly successful industry of marketing and selling non-medicinal remedies for women's sexual and reproductive health. ${ }^{1}$ The industry focuses on the female reproductive years from puberty through to menopause. It includes health-related products that promise to address women's sexual and reproductive concerns. However, these products can, and often do, fail to perform the promised function. In worst-case scenarios, they can cause damaging medical or psychological side-effects.

We use the 'Sexual and Reproductive Wellness Industry' (the industry) as an umbrella term to capture the kaleidoscope of businesses (large and small) operating within the field. This industry has received relatively little attention in the business and human rights (BHR)

\footnotetext{
${ }^{1}$ Here, we endeavour to be as inclusive as possible in our research, using an inclusive definition of 'female', 'woman', 'male' and 'man' as anyone who self-identifies with their chosen gender (or no gender). We also recognize that the majority of products in the sexual and reproductive wellness industry predominantly feature and are targeted at cis-gender women.

(c) The Author(s), 2022. Published by Cambridge University Press. This is an Open Access article, distributed under the terms of the Creative Commons Attribution licence (http://creativecommons.org/licenses/by/4.0), which permits unrestricted re-use, distribution and reproduction, provided the original article is properly cited.
} 
field. To the extent that sexual and reproductive wellness products are discussed, such scrutiny tends to focus on individual products or companies rather than on the industry as a whole. This is a problem because the industry is largely unregulated. As a result, it is able to target consumers with inappropriate marketing practices selling unnecessary or potentially harmful products. In this article, we propose that the industry should fall within the boundaries of the BHR scholarship as it has significant human rights implications that need to be addressed.

To be clear, this article is not advocating for modern medical and pharmaceutical interventions to the detriment of traditional or alternative medicine. We recognize the benefits of holistic approaches to health and the diverse cultural understandings of health that exist in communities around the world.

We identify the research agenda for this topic as requiring a fourfold approach: (1) to establish the landscape of the industry and use case studies to illuminate the legal and ethical problems within the industry; (2) to examine human rights principles to demonstrate the impact of an unregulated industry on human rights relating to access to sexual and reproductive healthcare and education; (3) to make the case that the sale and harmful marketing practices of the industry fall within the boundaries of the BHR scholarship; and (4) to engage in dialogue with interested parties and present a framework of solutions. We intend to address the first three objectives in this article and to open the fourth objective - the development of a framework of solutions - to the wider BHR community.

The article proceeds as follows. Part II establishes the landscape of the industry by identifying the wider wellness economy and distinguishing how neoliberal understandings of wellness are connected to female sexual and reproductive health, with a focus on personal responsibility, lack of regulation and privatized healthcare. To further cement our mapping of the industry, we then use several examples to illustrate the scope of existing products and companies and to identify four concerning dynamics present in the industry. Part III identifies human rights norms on sexual and reproductive health framed through the right to health and the right to education. Part IV uses a BHR framework to support the case that the industry in its current under- and unregulated form is harmful to the human rights of women and girls and, as such, should be more comprehensively addressed by the BHR community. Part V concludes by pointing towards a further BHR research agenda.

\section{Contextualizing the Sexual and Reproductive Wellness Industry}

\section{Wellness}

Wellness has become a buzzword. ${ }^{2}$ The origins and history of wellness practices span ancient and traditional approaches to health from across the globe. ${ }^{3}$ Wellness has been defined as the 'active pursuit of activities, choices and lifestyles that lead to a state of holistic health'. ${ }^{4}$ The term refers to proactively optimizing physical, mental, emotional (and often spiritual) 5 well-being as a whole, rather than just relying solely on curative strategies. It is a noticeably

\footnotetext{
${ }^{2}$ Anna Kirkland, 'What is Wellness Now?' (2014) 39:5 Journal of Health Politics, Policy and Law 957.

3 Ibid; Halbert L Dunn, 'High-Level Wellness for Man and Society' (1959) 49:6 American Journal of Public Health 786.

${ }^{4}$ Global Wellness Institute, 'What is Wellness?', https://globalwellnessinstitute.org/what-is-wellness/ (accessed 20 May 2020); Halbert L Dunn, High-Level Wellness: A Collection of Twenty-Nine Short Talks on Different Aspects of the Theme 'High-Level Wellness for Man and Society' (Arlington, VA: R. W. Beatty, 1961) 4-5.

${ }^{5}$ James William Miller, 'Wellness: The History and Development of a Concept' (2005) 27:1 Spektrum Freizeit 87.
} 
imprecise and malleable ideal, ${ }^{6}$ encapsulating vast areas of personal and social life. This is 'no small part of its marketing appeal."

Wellness encompasses interests such as fitness, nutrition and personal care. The wellness economy has exploded, valued at US $\$ 4.5$ trn globally in $2018 .{ }^{8}$ Although data on the industry as a whole are scarce, its growth has been attributed to many varied factors, including the promotion of 'clean eating', 9 digital and viral marketing, ${ }^{10}$ the increasing privatization and cost of healthcare (particularly in the United States of America (USA)), ${ }^{11}$ and the rise and personalization of wellness technology. ${ }^{12}$

Despite its permeation in everyday life, as an area of research, wellness has been largely overlooked in BHR scholarship. ${ }^{13}$ However, wellness culture, and in particular the commodification and promotion of wellness, is contested and problematic. Critical health and media studies scholarship has linked the pursuit of wellness or 'healthism' ${ }^{14}$ to the neoliberal ideal of the 'enterprising' individual. ${ }^{15}$ The commodification of everyday life and focus on individual responsibility has shaped how people think about themselves, including their bodies, sexuality and wellbeing, ${ }^{16}$ emphasizing 'consumer citizenship, personal responsibility and individual empowerment.'17 Drawing on the concept of governmentality, ${ }^{18}$ critical feminist health studies understand the body as a disciplinary site in and of itself, where neoliberal governance is enacted through hyper-individualized self-regulation and surveillance. ${ }^{19}$ Wellness is then perceived as the result of 'good choices made by morally autonomous and efficacious citizens'. ${ }^{20}$ Those who do not participate in

\footnotetext{
${ }^{6}$ Melanie Smith and Catherine Kelly, 'Wellness Tourism' (2006) 31:1 Tourism Recreation Research 1.

${ }^{7}$ Amy Larocca, 'The Wellness Epidemic: Why Are So Many Privileged People Feeling So Sick?', The Cut (26 June 2017), https://www.thecut.com/2017/06/how-wellness-became-an-epidemic.html (accessed 20 May 2020).

${ }^{8}$ Global Wellness Institute, 'Statistics and Facts', https://globalwellnessinstitute.org/press-room/statisticsand-facts/ (accessed 20 May 2020).

9 Brand Minds, 'The Health and Wellness Industry is Now Worth $\$ 4.2$ trillion', Medium (26 April 2019), https:// medium.com/manager-mint/the-health-wellness-industry-is-now-worth-4-2-trillion-866bf4703b3c (accessed 20 May 2020).

${ }^{10}$ Stefan Olof Lagrosen and Kerstin Grundén, ‘Social Media Marketing in the Wellness Industry' (2014) 26:3 TQM Journal 253.

${ }^{11}$ Heather Elliot, Jennifer Bernstein and Diana M Bowman, 'Wellness as a Worldwide Phenomenon' (2014) 39:5 Journal of Health Politics, Policy and Law 1067.

12 Brand Minds, note 9.

${ }^{13}$ Although see, in relation to extractive supply chains: Eva Wiseman, 'Are Crystals the New Blood Diamonds?', The Guardian (16 June 2019), https://www.theguardian.com/global/2019/jun/16/are-crystals-the-new-blood-dia monds-the-truth-about-muky-business-of-healing-stones (accessed 23 May 2020).

${ }^{14}$ Robert Crawford, 'Health as a Meaningful Social Practice' (2006) 10:4 Health: An Interdisciplinary Journal for the Social Study of Health, Illness and Medicine 401; Katie Cairns and Josée Johnston, 'Choosing Health: Embodied Neoliberalism, Postfeminisim, and the "Do-Diet"' (2015) 44:2 Theory and Society 153.

${ }^{15}$ We see neoliberalism as constituting not only an economic ideology, but a cultural one, emphasizing free market and privatization, and commodifying social worlds so as to resemble economic markets.

${ }^{16}$ Tycho Vandenburg and Virginia Braun, “'Basically, It's Sorcery for Your Vagina”: Unpacking Western Representations of Vaginal Steaming' (2016) 19:4 Culture, Health \& Sexuality 470.

${ }^{17}$ Jess Butler, ‘For White Girls Only?: Postmodernism and the Politics of Inclusion' (2013) 25:1 Feminist Formations 35,41 .

${ }^{18}$ Michel Foucault, 'Governmentality' in Graham Burchell, Colin Gordon and Peter Miller (eds.), The Foucault Effect: Studies in Governmentality (Chicago: University of Chicago Press, 1991) 87-104; Michel Foucault, 'The Political Technology of Individuals' in James Faubion (ed.), Michel Foucault: Power (New York: The New Press, 1994) 403-417.

${ }^{19}$ Cairns and Johnston, note 14.

${ }^{20}$ Christine Lavrence and Kristin Lozanski, “"This Is Not Your Practice Life”: Lululemon and the Neoliberal Governance of Self (2014) 51:1 Canadian Review of Sociology 76, 80.
} 
this pursuit are viewed as leading mismanaged lives. ${ }^{21}$ Self-improvement becomes both a moral responsibility for the individual, and a never-ending task. ${ }^{22}$

Various aspects of the wellness economy have also faced criticism for the promotion of 'diet culture', ${ }^{23}$ ableism, ${ }^{24}$ racism ${ }^{25}$ the co-option and distortion of traditional practices for profit, ${ }^{26}$ wellness as a form of social control, ${ }^{27}$ and the encouragement of an unattainable and often unaffordable lifestyle, reserved for a largely white and elite consumer base. ${ }^{28}$ Perhaps the most fundamental and underlying criticism is the wellness industry's lack of evidence-based approaches to health, which include the frequent blending of scientific language with pseudoscientific practices that aim to tackle nebulous symptoms such as 'inflammation', 'toxins' or 'free radicals'. ${ }^{29}$ Crucially, it is women who are most often the targets of wellness product marketing.

\section{Adverse Health Outcomes in Women}

'Women's bodies have been (and continue to be) a site of struggle for definition and control. ${ }^{30}$ The medical research gender gap means that less is known about women's bodies and health relative to men. ${ }^{31}$ Studies demonstrate that the implicit gender bias in medicine and medical research harms women, particularly women of colour. ${ }^{32}$ Global trust in

\footnotetext{
${ }^{21}$ Wendy Brown, 'Neoliberalism and the End of Liberal Democracy' (2003) 7:1 Theory and Event 37.

22 Vandenburg and Braun, note 16.

${ }^{23}$ Rosie Spinks, 'The Wellness Industry Thrives on the Fear of Death', QUARTZ (21 April 2018), https://qz.com/ quartzy/1256525/the-wellness-industry-thrives-on-the-fear-of-death/ (accessed 23 May 2020).

${ }^{24}$ Jessica Knoll, 'Smash the Wellness Industry', New York Times (8 June 2019), https://www.nytimes.com/2019/ 06/08/opinion/sunday/women-dieting-wellness.html (accessed 23 May 2020).

${ }^{25}$ Rina Raphael, 'Wellness Has a Diversity Issue: These Women Are Changing That', Fast Company (21 February 2018), https://www.fastcompany.com/40531531/wellness-has-a-diversity-issue-these-women-are-changing-that (accessed 24 May 2020); Nichole Cardoza, 'The Cover Shoot that Brought Me Face to Face with the Racism in the Wellness Industry', QUARTZ (10 October 2019), https://qz.com/quartzy/1723723/the-yoga-journal-cover-thatshowed-me-the-wellness-industrys-racism/ (accessed 24 May 2020).

${ }^{26}$ Jennifer Gunter and Sarah Parcak, 'Vaginal Eggs: Ancient Chinese Practice or Modern Marketing Myth?' (2019) 25:1 Female Pelvic Medicine \& Reconstructive Surgery 1.

${ }^{27}$ Anna Kirkland, 'Critical Perspectives on Wellness' (2014) 39:5 Journal of Health Politics, Policy and Law 971.

${ }^{28}$ Marisa Meltzer, 'Why Wellness is the New Way to Look, Feel and Act Rich', The Cut (18 July 2016), https:// www.thecut.com/swellness/2016/07/why-wellness-is-the-new-luxury-lifestyle-status-symbol.html (accessed 28 May 2020); Suzanne Bearne, 'Wellness: Just Expensive Hype, or Worth the Cost?', The Guardian (1 September 2018), https://www.theguardian.com/lifeandstyle/2018/sep/01/wellness-hype-superfoods-yoga-price (accessed 28 May 2020); Margaret McCartney, 'The Wellness Industry is Selling You the Myth that a Healthy Life is Expensive', The Guardian (2 January 2020), https://www.theguardian.com/commentisfree/2020/jan/02/wellness-industry-sell ing-healthy-life-expensive (accessed 28 May 2020).

${ }^{29}$ Jen Gunter, 'Worshipping the False Idols of Wellness', The New York Times (1 August 2018), https://www.ny times.com/2018/08/01/style/wellness-industrial-complex.html (accessed 2 January 2020); see also: Hadley Freeman, 'Pseudoscience and Strawberries: "Wellness" Gurus Should Carry a Health Warning', The Guardian (22 April 2015), https://www.theguardian.com/commentisfree/2015/apr/22/wellness-gurus-belle-gibson-pseudo science (accessed 24 May 2020); Bee Wilson, ‘Why I Fell for Clean Eating', The Guardian (11 August 2017), https:// www.theguardian.com/lifeandstyle/2017/aug/11/why-we-fell-for-clean-eating (accessed 20 May 2020).

${ }^{30}$ Virginia Braun and Sue Wilkinson, 'Socio-Cultural Representations of the Vagina' (2001) 19:1 Journal of Reproductive and Infant Psychology 17.

${ }^{31}$ Jennifer Block, Everything Below the Waist: Why Healthcare Needs a Feminist Revolution (New York: St Martin's Publishing Group, 2019).

32 Elizabeth G Nabel, ‘Coronary Heart Disease in Women - An Ounce of Prevention' (2000) 343:8 New England Journal of Medicine 572; Maya Dusenbery, Doing Harm: The Truth About How Bad Medicine and Lazy Science Leave Women Dismissed, Misdiagnosed, and Sick (New York: HarperCollins, 2018); Linda Villarosa, 'Why America's Black Mothers and Babies are in a Life-or-Death Crisis', The New York Times (11 April 2018), https://www.nytimes.com/2018/04/11/ magazine/black-mothers-babies-death-maternal-mortality.html (accessed 28 May 2020).
} 
mainstream healthcare is lower in women than in men, a gap that has continued to expand..$^{33}$ Iniquities can be particularly pronounced when it comes to sexual and reproductive healthcare. Almost 4.3 billion people of reproductive age have inadequate sexual and reproductive health services, ${ }^{34}$ and a disproportionate burden of sexual and reproductive ill-health falls on women and girls. ${ }^{35}$ According to the 2018 Guttmacher-Lancet Commission on reproductive health and rights, 200 million women globally have an unmet need for modern contraception and more than 45 million women receive inadequate or no antenatal care. ${ }^{36}$

Recent scandals concerning large pharmaceutical companies have also brought some of the harmful practices in conventional sexual and reproductive healthcare into sharp relief. Manufacturers of transvaginal mesh implants used in pelvic reconstructive surgery have been sued by women alleging serious health complications. ${ }^{37}$ Similarly, the Essure implant, a contraceptive manufactured by Bayer and marketed as a permanent, less invasive contraceptive solution, was taken off the market in 2018 after a global outcry from women who suffered devastating long-term side-effects. ${ }^{38}$ Bayer was also the subject of several class-action lawsuits. ${ }^{39}$ These cases exemplify the dangers of unsafe marketing practices, inadequate regulation, and corporate influence over female sexual and reproductive healthcare.

Compounding these issues is the educational and cultural context of sexual and reproductive health. While a woman's right to sexual and reproductive health forms an intrinsic part of international human rights law ${ }^{40}$ - further unpacked in Part III of this paper - there remain extensive disparities between sexual and reproductive health education for women, which vary from country to country (and even from school to school within countries), ${ }^{41}$ leaving inequitable knowledge gaps regarding women's health that wellness businesses step in to fill.

Studies have found that women overwhelmingly report normative body discontent, including concerning their genitalia. ${ }^{42}$ Patriarchal structures, which simultaneously stigmatize and objectify the female body and its sexual and reproductive functions - as

\footnotetext{
${ }^{33}$ Susan Isenberg, 'The Healthcare Trust Divide Widens', Edelman (22 April 2019), https://www.edelman.com/ research/healthcare-trust-barometer-widens (accessed 22 May 2020); Sophia Kercher, 'Why Don't Doctors Take Women's Pain Seriously?', Dame Magazine (19 March 2018), https://www.damemagazine.com/2018/03/19/whydont-doctors-take-womens-pain-seriously/ (accessed 21 May 2020).

${ }^{34}$ Ann M Starrs et al, 'Accelerate Progress-Sexual and Reproductive Health and Rights for All: Report of the Guttmacher-Lancet Commission' (2018) 391 The Lancet 2642.

${ }^{35}$ Manjulaa Narasimhan et al, 'Investing in Sexual and Reproductive Health and Rights of Women and Girls to Reach HIV and UHC Goals' (2018) 6:10 The Lancet Global Health E1058.

${ }^{36}$ Starrs et al, note 34 .

${ }^{37}$ Michelle Llamas, 'Transvaginal Mesh Verdicts and Settlements', Drugwatch (28 June 2020),

https://www.drugwatch.com/transvaginal-mesh/verdict-settlement/ (accessed 10 August 2020).

${ }^{38}$ Hannah Devlin, 'Contraceptive Implant Surgically Removed from Thousands of Women', The Guardian (25 November 2018), https://www.theguardian.com/society/2018/nov/25/contraceptive-implant-essure-surgi cally-removed-from-thousands-women (accessed 10 August 2020).

39 Drugwatch, 'Essure Lawsuits', https://www.drugwatch.com/essure/lawsuits/ (accessed 19 October 2021).

${ }^{40}$ Aart Hendriks, 'Promotion and Protection of Women's Right to Sexual and Reproductive Health under International Law: The Economic Convent and the Women's Convention: Conference on the Interventional Protection of Reproductive Rights: The Right to Health' (1995) 44:4 American University Law Review 1123.

${ }^{41}$ Hildie Leung et al, 'Development of Contextually Relevant Sexuality Education: Lessons from a Comprehensive Review of Adolescent Sexuality Education Across Cultures' (2019) 16:4 International Journal of Environmental Research and Public Health 621.

42 Breanne Fahs, ‘Genital Panics: Constructing the Vagina in Women's Qualitative Narratives About Pubic Hair, Menstrual Sex, and Vaginal Self-Image' (2014) 11:3 Body Image 210.
} 
exemplified by the concealment of menstruation, ${ }^{43}$ taboos surrounding female sexual pleasure or the idea that female genitalia are unclean ${ }^{44}$ - remain prevalent. ${ }^{45}$

\section{The Sexual and Reproductive Wellness Industry}

With this context in mind, we turn to the female sexual and reproductive wellness industry. ${ }^{46}$ Critical feminist health scholarship extends the discussion on how the neoliberal 'enterprising self' is enacted and regulated through the eternal pursuit of wellness (as discussed above), to look specifically at the impact of this on the female sexual and reproductive body. In her work, Jane Ussher builds on earlier feminist theorizing to argue that the reproductive body is seen as both central to the performance of normative femininity and as an embodied pathology. ${ }^{47}$

Folded in with and concealed by the surveillance and regulation of the sexual and reproductive self, ${ }^{48}$ is the development of the postfeminist rhetoric of choice and empowerment and the popularization of 'commodity feminism'. ${ }^{49}$ Here, the ability of women to make choices and to be empowered is demonstrated through their participation in the market economy. Feminist ideals of body positivity and self-care, traditionally understood as emancipatory and collectivist acts, ${ }^{50}$ are commodified and individualized. ${ }^{51}$ Rosalind Gill maintains that the discourse of empowerment is highly marketable, inviting women to "purchase everything from bras to coffee as a sign of their power and independence'. ${ }^{52}$ Indeed, this has become central to how wellness is marketed to women, ${ }^{53}$ with products like rejuvenation injections claiming to 'empower the vagina'. ${ }^{54}$

\footnotetext{
${ }^{43}$ See Emily Martin, The Woman in the Body: A Cultural Analysis of Reproduction (Boston, MA: Beacon Press, 1987); Karen Houppert, The Curse: Confronting the Last Unmentionable Taboo: Menstruation (London: Profile, 1999); Ingrid Johnston-Robledo et al, 'Reproductive Shame: Self-Objectification and Women's Attitudes Toward Their Reproductive Functioning' (2007) 46:1 Women's Health 25; Ingrid Johnston-Robledo and Joan C Chrisler, 'The Menstrual Mark: Menstruation as Social Stigma' (2013) 68:1-2 Sex Roles 9; Anna Pujol-Mazzini, 'For Refugee Women, Periods are a Dangerous, Shameful Time', Reuters (8 March 2017), https://www.reuters.com/article/us-womensday-refugees-periods-feature/for-refugee-women-periods-a-dangerous-shameful-time-idUSKBN16F1UU (accessed 29 May 2020); Chris Bobel, The Managed Body: Developing Girls and Menstrual Health in the Global South (Cham, Switzerland: Palgrave Macmillan, 2019).

${ }^{44}$ Braun and Wilkinson, note 30.

${ }^{45}$ Vandenburg and Braun, note 16.

${ }^{46}$ Although there are also products available which target male sexual and reproductive health - particularly those geared at erectile function - the focus of this piece is on products directed at women.

47 Jane Ussher, Managing the Monstrous Feminine: Regulating the Reproductive Body (Hove: Routledge, 2006) 4. See also Judith Butler, Gender Trouble: Feminism and the Subversion of Identity (London: Routledge, 1990).

${ }^{48}$ Vandenburg and Braun, note 16.

${ }^{49}$ Rosalind Gill, 'Commodity Feminism', The International Encyclopedia of Communication (5 June 2008),

https://onlinelibrary.wiley.com/doi/abs/10.1002/9781405186407.wbiecc055 (accessed 29 December 2020).

${ }^{50}$ Eva Chen, 'Neoliberalism and Popular Women's Culture: Rethinking Choice, Freedom and Agency' (2013) 16:4 European Journal of Cultural Studies 440.

${ }^{51}$ Rosalind Gill, 'Empowerment/Sexism: Figuring Female Sexual Agency in Contemporary Advertising' (2008) 18:1 Feminism \& Psychology 35; Michelle M Lazar, 'The Right to Be Beautiful: Postfeminist Identity and Consumer Beauty Advertising' in Rosalind Gill and Christina Scharff (eds.), New Femininities (London: Palgrave Macmillan, 2011) 37; Ela Przybylo and Breanne Fahs, 'Empowered Bleeders and Cranky Menstruators: Menstrual Positivity and the “Liberated” Era of New Menstrual Product Advertisements' in Chris Bobel et al (eds.), The Palgrave Handbook of Critical Menstrual Studies (London: Palgrave MacMillan, 2020) 375; Chen, note 50.

${ }^{52}$ Gill, note 49, 36.

${ }^{53}$ Vandenburg and Braun, note 16.

${ }^{54}$ Suzannah Weiss, 'I Got Six Shots in My Vagina in The Name of Empowerment', ELLE (7 April 2017), https:// www.elle.com/life-love/sex-relationships/a44292/i-got-6-shots-in-my-vagina-in-the-name-of-empowerment/ (accessed 9 October 2020).
} 
In this way, the industry has co-opted both the fears around women's sexual health and fertility, and the emancipatory principles that sought to liberate women from their sexual and reproductive roles. As Morgan succinctly contends, 'The tacit suggestion that we are not loving ourselves enough unless we spend the money to try to give our vulvas the tone and luminosity of a cheekbone or a shoulder is, surely, a phenomenon worthy of great concern.' 55

Given the expansive definition of wellness, products in the industry are extensive. They range from 'Femtech', ${ }^{56}$ hygiene products, sexual health products, beauty products and cosmetic genital treatments. These products cater to (and to some extent, help to control) every stage of a woman's reproductive life cycle, including fertility-enhancing, ante-natal, postpartum and menopause treatments. Many centre on the use of eco-friendly materials, such as menstrual cups, organic tampons and CBD lubrication. ${ }^{57}$ Others boast holistic benefits like detoxing and purification. ${ }^{58}$ Retailers range from individual sellers on e-commerce platforms such as Etsy, to large, international lifestyle and wellness brands. ${ }^{59}$ Typically, products in this industry are classified as cosmetic rather than medical devices or pharmaceuticals - even though many of them are meant for internal use - meaning that companies are largely unregulated..$^{60}$

In addition to the control and commodity aspects of the industry discussed above, the misinformation produced by the industry has significant human rights implications. We discuss these below with reference to specific examples.

\section{Industry Examples}

As the contours of the industry are rather amorphous, we draw on three illustrative examples - Goop's Jade Egg, LadyCare's Menopause Magnets and Goddess Detox's Vaginal Detox Pearls. The three products were chosen because they provide axiomatic examples of the types of products and companies at play and how these can harm women and girls throughout their reproductive life cycle. All of the products have been under investigation for false advertising in different domestic jurisdictions, where approaches to the regulation of deceptive marketing vary. Using these examples as a guide, we then identify dynamics of the industry that are of particular concern in a BHR context.

\section{Goop's Jade Egg}

Goop's Jade Egg (or 'Yoni' Egg) is perhaps the most infamous of the industry products. Released around 2017, the US\$66 nephrite jade egg is inserted vaginally and is advertised

\footnotetext{
${ }^{55}$ Eleanor Morgan, 'Vulva Masks and Labia Serums: The Marketing of Women's Shame', The Guardian (20 February 2020), https://www.theguardian.com/lifeandstyle/2020/feb/20/vulva-masks-and-labia-serumsthe-marketing-of-womens-genital-shame (accessed 9 October 2020).

${ }^{56}$ Donna Lu, 'The Femtech Goldrush' (2019) 242:3232 New Scientist 20.

${ }^{57}$ Jessica Bissell-Linsk, 'Organic Tampons Escalate Battle in Feminine Care', Financial Times (28 May 2018), https://www.ft.com/content/a4aeb28a-5490-11e8-b24e-cad6aa67e23e (accessed 29 May 2020).

${ }^{58}$ Rose George, ‘The Vagina is Self-Cleaning - So Why Does the 'Feminine Hygiene' Industry Exist?', The Guardian (4 September 2018), https://www.theguardian.com/society/2018/sep/04/the-vagina-is-self-cleaning-so-whydoes-the-feminine-hygiene-industry-exist (accessed 10 August 2020).

59 Chris Morris, ‘Gwyneth Paltrow’s Company Goop is Now Valued at \$250 Million’, Fortune (30 March 2018), https://fortune.com/2018/03/30/gwyneth-paltrow-goop-series-c-valuation-250-million/ (accessed 10 August 2020).

${ }^{60}$ See, e.g., Joo-Young Lee and Paul Hunt, 'Human Rights Responsibilities of Pharmaceutical Companies in Relation to Access to Medicines' (2012) 40:2 Journal of Law, Medicine and Ethics 220.
} 
in the United Kingdom (UK) as capable of harnessing 'the power of energy work, crystal healing, and a Kegel-like physical practice. ${ }^{61}$ Both Goop Inc. and the Egg have been the subject of fierce criticism. Goop has a history of marketing strategies that co-opt or distort scientific language and combine evidence with folklore and anecdotes in a way that is difficult to regulate. ${ }^{62}$ Goop contends that it is careful to avoid making statements of medical fact, instead emphasizing that its purpose as a wellness lifestyle company is to 'ask questions' about conventional approaches to women's health and well-being. ${ }^{63}$ It claims to compile and offer a variety of alternative information about, and solutions for, sexual and reproductive health, allowing consumers to draw their own conclusions. ${ }^{64}$ This approach combines the neoliberal ideal of female empowerment and choice rhetoric $^{65}$ while highlighting that women's sexual and reproductive issues have been overlooked by conventional healthcare: 'Our primary place is in addressing people, women in particular, who are tired of feeling less-than-great, who are looking for solutions - these women are not hypochondriacs, and they should not be dismissed or marginalized.' 66

The Jade Egg was previously advertised online as having the ability to 'balance hormones, regulate menstrual cycles, prevent uterine prolapse, and increase bladder control'. ${ }^{67}$ This generated a strong backlash in the media and healthcare. ${ }^{68}$ Medical practitioners have repeatedly stated that aside from the Egg's implausible claims on its impact on genital health, ${ }^{69}$ its use might also be harmful. ${ }^{70}$

In 2018, Goop settled a case with the California Food, Drug and Medical Device Task Force, where the company was ordered to pay US $\$ 145,000$, and refund customers for the Egg and another deceptively marketed product. ${ }^{71}$ Perhaps most significantly of all, Goop was also precluded from making or disseminating deceptive claims and statements about any of its products for five years. ${ }^{72}$

\footnotetext{
${ }^{61}$ Goop Wellness, 'Jade Egg', https://shop.goop.com/shop/products/jade-egg?country=GBR (accessed 10 August 2020).

${ }^{62}$ Rae Paoletta, 'NASA Calls Bullshit on Goop’s \$120 “Bio-Frequency Healing” Sticker Packs', Gizmodo (22 June 2017), https://gizmodo.com/nasa-calls-bullshit-on-goops-120-bio-frequency-healing-1796309360?utm_campaign=socialflow_ gizmodo_twitter\&utm_source=gizmodo_twitter\&utm_medium=socialflow (accessed 10 August 2020).

63 Taffy Brodesser-Akner, 'How Goop's Haters Made Gwyneth Paltrow's Company Worth \$250 Million', The New York Times (25 July 2018), https://www.nytimes.com/2018/07/25/magazine/big-business-gwyneth-paltrowwellness.html (accessed 10 August 2020).

${ }^{64}$ Cheryl Wischhover, "Goop is Categorizing its Wellness Stories from "Rigorously Tested" to "For Your Enjoyment”, Racked (15 June 2018), https://www.racked.com/2018/6/15/17464614/goop-gwyneth-paltrow-skin care-supplements-transparency (accessed 10 August 2020).

${ }^{65}$ Chen, note 50.

${ }^{66}$ Goop Wellness, 'Uncensored: A Word From Our Contributing Doctors', https://goop.com/wellness/health/ uncensored-a-word-from-our-doctors/ (accessed 10 August 2020).

67 TINA.org, 'California Cracks Down on Goop after TINA.org Complaint' (4 September 2018), https://www. truthinadvertising.org/california-cracks-down-on-goop-after-tina-org-complaint/ (accessed 10 August 2020).

${ }^{68}$ See Kirsten V Brown, 'No, You Should Not Put Jade Eggs in Your Vagina Because Gwyneth Paltrow Tells You To', Gizmodo (19 January 2017), https://gizmodo.com/no-you-should-not-put-jade-eggs-in-your-vagina-because1791390211 (accessed 10 August 2020); Jen Gunter, 'Dear Gwyneth Paltrow, I’m a GYN and Your Vaginal Jade Eggs are a Bad Idea', drjengunter.com (17 January 2017), https://drjengunter.com/2017/01/17/dear-gwyneth-paltrow-im-agyn-and-your-vaginal-jade-eggs-are-a-bad-idea/ (accessed 5 August 2020).

${ }^{69}$ Gunter and Parcak, note 26.

${ }^{70}$ Gunter, note 68.

${ }^{71}$ People of the State of California $v$ Goop, Inc., 18-cv-001176 Cal. Sup. (2018).

72 Ibid, 4-5.
} 


\section{LadyCare's Menopause Magnet}

LadyCare's Menopause Magnet is a UK£45 device that relies on magnet therapy to treat symptoms of perimenopause and menopause. It is designed to clip into underwear and to be worn every day for at least three months. ${ }^{73}$ Magnet therapy is reportedly a billion-dollar industry ${ }^{74}$ with little evidence-based science to back up curative claims. ${ }^{75}$ The LadyCare Magnet is advertised as proven to reduce or eliminate menopause symptoms (such as hot flashes, night sweats, weight gain and mood swings) in 'over 71 percent of women', by 'restoring balance' in the automatic nervous system. ${ }^{76}$ The efficacy of these claims has been frequently contested, most recently by the UK's Advertising Standards Agency, which decided that advertising the Magnet in such a misleading manner breached the Code of Non-Broadcast Advertising and Direct \& Promotional Marketing. ${ }^{77}$

While LadyCare contended that their website described the outcome of clinical trials and reported observations, they produced no evidence to that effect. ${ }^{78}$ The Magnets continue to be sold online, with many of the original claims intact.

\section{Goddess Detox Vaginal Detox Pearls}

Goddess Inc.'s Detox Pearls are US\$33 herbal vaginal suppositories, which work to aid 'overall womb health' by expelling contents that may be 'working against the womb and vagina'. ${ }^{79}$ These products form part of a wider trend of 'vaginal steaming' using the application of herbs and heat. ${ }^{80}$ The practice has similarities to other home remedies, ${ }^{81}$ but has been rapidly commercialized, with contemporary products often promoted to treat serious medical conditions like uterine prolapse. ${ }^{82}$ Apart from the fact that the vagina does not require detoxing, ${ }^{83}$ the use of steaming products has in some cases led to significant harm, causing second-degree burns. ${ }^{84}$

The list of the Goddess Detox Pearls' supposed benefits ranges from increasing libido and fertility, to 'detoxing a consumer's ex-partner' ${ }^{85}$ In 2019, Canada's public health department

\footnotetext{
${ }^{73}$ LadyCare Menopause, 'LadyCare Plus', https://www.ladycare-uk.com/shop/menopause-relief/ladycareplus/ (accessed 7 August 2020).

74 'Magnet Therapies Have "No Effect”, BBC News (6 January 2006), http://news.bbc.co.uk/1/hi/health/ 4582282.stm (accessed 7 August 2020).

${ }^{75}$ Janet S Carpenter and Jennifer G Neal, 'Other Complementary and Alternative Medicine Modalities: Acupuncture, Magnets, Reflexology and Homeopathy’ (2005) 118:12 The American Journal of Medicine 109; Sherry Sherman et al, 'Research Opportunities for Reducing the Burden of Menopause-Related Symptoms' (2005) 118:12 The American Journal of Medicine 166.

${ }^{76}$ LadyCare Menopause, 'LadyCare Pulse May Reduce or Completely Eliminate All Menopause Symptoms in Over 71\% of Women', https://www.ladycare-uk.com/ (accessed 7 August 2020).

77 ASA, 'ASA Ruling on LadyCare Lifetime Ltd', https://www.asa.org.uk/rulings/ladycare-lifetime-ltd-A19478758.html (accessed 7 August 2020).

${ }^{78}$ Ibid.

${ }^{79}$ Goddess Detox, 'Goddess Vaginal Detox Pearls', https://goddessdetox.org/products/goddessvaginaldetox pearls (accessed 19 October 2021).

${ }^{80}$ Vandenburg and Braun, note 16.

81 Ibid.

${ }^{82}$ Magali Robert, 'Second-Degree Burn Sustained After Vaginal Steaming' (2019) 41:6 Journal of Obstetrics and Gynaecology Canada 838.

${ }^{83}$ Katie Way, “'Detox Pearls” Absolutely Do Not Belong in Anyone's Vagina', Vice (8 November 2019), https:// www.vice.com/en_us/article/xwe9zz/detox-pearls-absolutely-do-not-belong-in-anyones-vagina (accessed 7 August 2020).

${ }^{84}$ Robert, note 82.

${ }^{85}$ Wendy Weiss $v$ Goddess Detox, Inc, CACE 20-202330 Fla. Cir., Broward Cty (2020).
} 
barred the sale of the Pearls due to their deceptive marketing practices. ${ }^{86}$ Concerns over the Pearls' purported trauma-healing properties were also raised by the Canadian Women's Foundation, who stated that: 'Healing and cleansing "aids" that make claims ungrounded in research can mislead people, create confusions and compound vulnerability. It causes even more harm to survivors of violence.' 87

In 2020, a class-action lawsuit was filed in Florida against Goddess Inc., claiming that the Pearls' marketing and advertising were false and misleading. The claimants also contend that some of the listed ingredients have not been established as safe for internal use, exposing consumers to the risk of significant bodily harm. ${ }^{88}$ They further argue that claiming the product can treat infertility is unlawful, as infertility is a medical condition, and treatment of such a condition must be approved by a federal agency, the United States Food and Drug Association. ${ }^{89}$

\section{Marketing Practices of Concern}

From the above examples, we can delineate several features of the marketing practices employed by companies in the industry which are of particular concern from a human rights perspective and arguably therefore also of interest to the BHR field.

First, product advertisement is often infused with a combination of scientific language and holistic vocabulary. In the above cases, language such as 'Kegel-like', 'detoxifying' and 'restoring balance to the automatic nervous system' through magnetic fields is used. These phrases are a form of 'scienceploitation' that can 'mislead the public and make it difficult to discern real science from marketing claims that merely reference scientific-sounding terminology. ${ }^{90}$

Second, marketing practices directly exploit the lack of understanding and dismissal of women's bodies in conventional healthcare, manipulating perennial misogynistic beliefs about female bodies as 'unclean' and in need of constant surveillance, for profit. ${ }^{91}$ It perpetuates false information in the form of pseudoscientific health myths (dressed up as 'wellness'), which have the potential to directly harm women. They prey on shame and body insecurities and encourage personal hyper-surveillance of genitalia to control anything that might be perceived as 'abnormal', with each product resting on the assumption that women's sexual and reproductive organs require fixing. The three products discussed above are indicative of a harmful trend in the industry, particularly as unsubstantiated marketing claims may be relied upon by people making health-related decisions when they are advertised by those who have a commercial interest in profiting from misinformation, and when those interests are not properly regulated.

Finally, the growth of digital marketing practices via social media provides an effective vehicle for marketing sexual and reproductive wellness products, given the potential for both a wide reach and targeted advertisements. ${ }^{92}$ The rise of 'influencer culture', and

\footnotetext{
${ }^{86}$ Jenny Cowley and Charlsie Agro, “"Very Predatory”: Health Canada Bars Sale of Vaginal Detox Products Following Marketplace Investigation', CBC News (8 November 2019), https://www.cbc.ca/news/health/vtoxhealth-marketplace-1.5347367 (accessed 7 August 2020).

${ }^{87}$ Ibid.

${ }^{88}$ Wendy Weiss $v$ Goddess Detox, Inc, note 85.

${ }^{89}$ Ibid, 5 .

${ }^{90}$ Blake Murdoch, Amy Zarzeczny and Timothy Caulfield, 'Exploiting Science? A Systematic Analysis of Complementary and Alternative Medicine Clinic Websites’ Marketing of Stem Cell Therapies' (2018) 8:2 BMJ Open 1,10 .

${ }^{91}$ Vandenburg and Braun, note 16.

92 The spread of misinformation via digital platforms, particularly in relation to health during the COVID-19 pandemic, is a growing human rights concern; see UN Department of Global Communications, 'UN Tackles
} 
celebrity endorsements has been advantageous for the marketing of misinformation online, ${ }^{93}$ where the consumer seeks to buy into a certain lifestyle, rather than assessing whether the product itself is effective or safe. ${ }^{94}$ For example, Goop - owned by actor and guru, Gwyneth Paltrow - is built on the aspirational and very marketable ideal that buying Goop's products is akin to owning Paltrow's lifestyle and that of her influential (white and wealthy) friends. ${ }^{95}$ LadyCare has also used celebrity endorsements, ${ }^{96}$ and The Goddess Detox heavily relies on marketing via social media, touting numerous positive consumer product reviews. ${ }^{97}$

In spotlighting these three industry products, and exploring common features that are of particular concern, we pave the way for Parts III and IV below, which highlight the right to sexual and reproductive health and the potential for using a BHR framework to observe, prevent and remedy some of these harms in the industry.

\section{Sexual and Reproductive Health and Education Rights in International Human Rights Law}

\section{Sexual and Reproductive Health}

This article demonstrates that states are failing to respect, protect and facilitate the right to health for women and girls..$^{98}$ One outcome of this failure is that businesses are given freedom to define the boundaries of female sexual and reproductive health and wellness without any real accountability for the harms that they might cause. Neoliberal regulatory approaches have created unequal health and educational systems that provide fertile ground for the predatory corporate marketing of sexual and reproductive wellness products. ${ }^{99}$ These are human rights issues that must be addressed by states and by businesses.

Sexual and reproductive health rights (SRHR) includes 'The right to have control over and decide freely and responsibly on matters relating to sexuality, including sexual and

\footnotetext{
"Infodemic" of Misinformation and Cybercrime', UN COVID-19 Responses (31 March 2020), https://www.un.org/ en/un-coronavirus-communications-team/un-tackling-\%E2\%80\%98infodemic\%E2\%80\%99-misinformation-andcybercrime-covid-19 (accessed 19 October 2021); Elena Abrusci, Sam Dubberley and Lorna McGregor, 'An "Infodemic" in the Pandemic: Human Rights and Covid-19 Misinformation' in Carla Ferstman and Andrew Fagan (eds.), Covid-19, Law and Human Rights: Essex Dialogues - A Project of the School of Law and Human Rights Centre (Essex: University of Essex, 2020) 287; for a definition of 'misinformation', see Claire Wardle and Hossein Derakhshan, 'Information Disorder: Towards an Interdisciplinary Framework for Research and Policy Making', Council of Europe Report DGI(2017)09 (2017), https://rm.coe.int/information-disorder-toward-an-interdisciplinary-framework-forresearc/168076277c (accessed 19 October 2021); Christian Fuchs, 'Social Media, Big Data, and Critical Marketing', in Mark Tadajewski et al (eds.), The Routledge Companion to Critical Marketing (London: Routledge, 2018).

93 Kelly D Martin and Craig N Smith, 'Commercializing Social Interaction: The Ethics of Stealth Marketing' (2008) 27 Journal of Public Policy and Marketing 1, 45.

${ }^{94}$ See Isabel Ebert and Dana Sindermann, 'An Ethical View on Influencer Marketing - Dynamic Interaction Between Individual and Economy or a Simple Data-Driven Advertising Model?' in Catalina Goanta and Sofia Ranchordás (eds.), The Regulation of Social Media Influencers (London: Routledge, 2020) 74; Timothy Caulfield, The Science of Celebrity...or Is Gwyneth Paltrow Wrong About Everything? (Toronto: Penguin, 2015).

95 Sady Doyle, 'Gwyneth, Ivanka, and the End of the Effortless White Woman', Medium (31 July 2018), https:// gen.medium.com/gwyneth-ivanka-and-the-end-of-the-effortless-white-woman-9d8c4e01a026 (accessed 9 October 2020).

${ }^{96}$ Ella Alexander, 'Belinda Carlisle Stops Her Menopausal Flushes With Mysterious Miracle Magnet', The Independent (24 June 2014), https://www.independent.co.uk/news/people/belinda-carlisle-stops-her-meno pausal-flushes-mysterious-miracle-magnet-9559370.html (accessed 9 October 2020).

${ }^{97}$ Goddess Detox, 'Reviews', https://goddessdetox.org/pages/reviews-1 (accessed 9 October 2020).

${ }^{98}$ See Part II.

99 Ibid.
} 
reproductive health, free of coercion, discrimination and violence ... and the right to attain the highest standard of sexual and reproductive health. ${ }^{100}$ States have obligations under international human rights law to respect, protect and fulfil the SRHR of women and girls. The global health community has also developed professional standards and ethical codes that support medical practitioners taking a proactive role in safeguarding access to health information and in countering misinformation. ${ }^{101}$ While SRHR apply to everyone, the realization of these rights for women and girls is of particular importance due to their centrality for the achievement of gender equality. ${ }^{102}$ As noted in Part II of this paper, women and girls during their reproductive years form the demographic most at risk of being targeted by businesses in the female wellness industry.

In 2010, the Committee on the Elimination of All Forms of Discrimination Against Women (CEDAW) issued General Recommendation (No. 28) ${ }^{103}$ on the core obligations of states parties under the Convention noting that 'Article 2 is not limited to the prohibition of discrimination against women caused directly or indirectly by States parties. Article 2 also imposes a due diligence obligation to prevent discrimination by private actors. ${ }^{104}$ States parties are obliged, inter alia, to regulate the 'activities of private actors with regard to education, employment and health policies'. ${ }^{105}$ States parties are further obliged to 'promote the equal rights of girls since girls ... are more vulnerable to discrimination in such areas as access to basic education ... and States shall pay attention to the specific needs of (adolescent) girls by providing education on sexual and reproductive health'. ${ }^{106}$

SRHR are therefore well-established human rights norms that entail obligations for states and responsibilities for non-state actors, including businesses, to ensure that they are respected and protected without any discrimination.

\section{Right to Health}

The right to health is recognized in several key international treaties, including the International Covenant on Economic, Social and Cultural Rights (CESCR). ${ }^{107}$ General Comment No. 14 on Article 12 of CESCR recognizes the gender gap in healthcare by advising

\footnotetext{
${ }^{100}$ International Planned Parenthood Federation (IPPF), 'Sexual and Reproductive Health and Rights - the Key to Gender Equality and Women's Empowerment' (2015), https://www.ippfen.org/sites/ippfen/files/2016-12/Vision\% 202020\%20Gender\%20Report.pdf (accessed 11 August 2020) 2.

${ }^{101}$ World Medical Association, 'WMA International Code of Medical Ethics' (1949), https://www.wma.net/ policies-post/wma-international-code-of-medical-ethics/ (accessed 19 October 2021).

${ }^{102}$ UN Office of the High Commissioner, 'What Are Human Rights?', https://www.ohchr.org/en/issues/pages/ whatarehumanrights.aspx (accessed 19 October 2021); Gillian McNaughton, 'Untangling Equality and NonDiscrimination to Promote the Right to Health Care for All' (2009) 11:2 Health and Human Rights Journal 47; Kristina Areskoug-Josefsson et al, 'Education for Sexual and Reproductive Health and Rights (SRHR): A Mapping of SRHRRelated Content in Higher Education in Health Care, Police, Law and Social Work in Sweden' (2019) 19:6 Sex Education 720; Tedros Adhanom Ghebreyesus and Natalia Kanem, 'Defining Sexual and Reproductive Health and Rights for All' (2018) 391:10140 The Lancet 2583; Starrs et al, note 34.

${ }^{103}$ UN Committee on the Elimination of Discrimination Against Women, 'General Recommendation No. 28 on the Core Obligations of States Parties under Article 2 of the Convention on the Elimination of All Forms of Discrimination Against Women', CEDAW/C/GC/28 (16 December 2010).

${ }^{104}$ Ibid, para 13.

${ }^{105}$ Ibid.

106 Ibid, para 21.

107 See, e.g., International Convention on Economic, Social and Cultural Rights, UN Doc 993 UNTS (adopted on 16 December 1966, entered into force on 3 January 1976) art 12; International Convention on the Elimination of All Forms of Racial Discrimination, UN Doc. 660 UNTS 195 (adopted 21 December 1965, entered into force 4 January 1969) art 5(e)(iv); Convention on the Elimination of All Forms of Discrimination Against Women, UN Doc 1249 UNTS (adopted on 18 December 1979, entered into force 3 September 1981) arts 11(1)(f), 12 and 14(2)(b); Convention on
} 
states that they should integrate a gender-based perspective in their health-related policies, planning, programmes and research in order to promote better health for both women and men. ${ }^{108}$ The general comment clarifies that to remove discrimination against women, 'there is a need to develop and implement a comprehensive national strategy for promoting women's right to health throughout their life ... [t] he realization of women's right to health requires the removal of all barriers interfering with access to health services, education and information including in the area of sexual and reproductive health. ${ }^{109}$

In 2016, in response to its observed violations of SRHR, the CESCR Committee issued its interpretive General Comment (No. 22), clarifying that SRHR are an 'integral' part of the right to health. ${ }^{110}$ Women and girls are highlighted particularly because of their reproductive capacities ${ }^{111}$ and, as demonstrated in Part II, it is especially because of these capacities that an industry has developed to tap into the associated special needs of women. For there to be gender parity in sexual and reproductive health, 'the health needs of women, different from those of men'112 must be considered and this applies to protection from harmful products aimed at women due to their sexual and reproductive biology. The CESCR Committee reminds states of their obligation to ensure 'to the maximum of their available resources, with a view to achieving progressively the full realization of the right to sexual and reproductive health ... [s] uch steps should ... [use] all appropriate means, particularly including, but not limited to, the adoption of legislative and budgetary measures. ${ }^{113}$ In this context, we argue that manufacturers of goods or services relating to women's sexual and reproductive health should be subject to appropriate regulation and accountability frameworks.

The highest attainable standard of sexual and reproductive health can only be realized through equal access to public health services. The risk that someone will self-diagnose and self-treat increases in healthcare systems rooted in neoliberal approaches and increases again when the complaint relates to sexual and reproductive health where there is stigma and a lack of education surrounding what is 'normal'. Consequently, access to healthcare is connected to the right to education and it is for this reason that to fully realize health rights we must also consider rights to education and information so that women and girls are able to make informed choices about their SRHR.

\section{Right to Education}

Education is recognized as a human right in numerous international and regional instruments. ${ }^{114}$ The Convention on the Elimination of Discrimination Against Women

\footnotetext{
the Rights of the Child, UN Doc. 1577 UNTS (adopted on 20 November 1989, entered into force on 2 September 1990) art 24.

${ }^{108}$ Committee on Economic, Social and Cultural Rights, 'CESCR General Comment No. 14: The Right to the Highest Attainable Standard of Health (Article 12 of the International Covenant on Economic, Social and Cultural Rights)', Doc. E/C.12/2000/4 (11 August 2000) para 20.

109 Ibid, para 21.

${ }^{110}$ Committee on Economic, Social and Cultural Rights, 'CESCR General Comment No. 22 (2016) on the Right to Sexual and Reproductive Health (Article 12 of the International Covenant on Economic, Social and Cultural Rights)', Doc. E/C.12/GC/22 (2 May 2016); International Justice Resource Center, 'CESCR Issues Guidance on Right to Sexual and Reproductive Health' (16 March 2016), https://ijrcenter.org/2016/03/16/the-cescr-addresses-the-right-tosexual-and-reproductive-health/ (accessed 25 August 2020).

${ }^{111}$ Ibid, para 25.

112 Ibid.

113 Ibid, para 33.

114 See, e.g., Convention on the Rights of the Child, note 107, art 13; Protocol to the African Charter on Human and Peoples' Rights on the Rights of Women in Africa (adopted on 11 July 2003, entered into force on 25 November 2005),
} 
(CEDAW) interpretation of education is particularly important because of historical gender discrimination against girls. Article $10(\mathrm{~h})$ stipulates that states must ensure that there is '[a]ccess to specific educational information to help to ensure the health and well-being of families, including information and advice on family planning. ${ }^{115}$ In 2017, the CEDAW Committee issued General Recommendation No. 36 on girls' and women's right to education which states that '[a]s a human right, education enhances the enjoyment of other human rights and freedoms, yields significant development benefits [and] facilitates gender equality.'116

The CESCR Committee interprets the determinants of SRHR as including access to 'healthrelated education and information'. ${ }^{117}$ Information 'related to sexual and reproductive health care should be accessible to all individuals and groups without discrimination and free from barriers'. ${ }^{118}$ All 'individuals and groups, including adolescents and youth, have the right to evidence-based information on all aspects of sexual and reproductive health'.119 States are under an obligation to ensure that SRHR is 'evidence-based and scientifically and medically appropriate and up-to-date.'120

As was highlighted in Part I, there is a gap in medical research, knowledge and understanding of women's bodies relative to men's bodies. ${ }^{121}$ One critical contributor to this dearth of understanding is the lack of a cohesive international approach to sexual and reproductive health education. Differences occur from country to country and even from school to school within a single country. ${ }^{122}$ A global review undertaken by UNESCO in 2015 states that core elements of comprehensive sexuality education (CSE) 'share certain similarities: CSE's firm grounding in human rights - including the rights of the child, and the empowerment of children and young people - and a reflection of the broad concept of sexuality as a natural part of human development.' ${ }^{123}$ The report also notes that 'young people are increasingly demanding their right to sexuality education'. ${ }^{124}$ Furthermore, the report recognizes the commitments that various governments have made and the increasing political will to 'scale up delivery of CSE' with partnerships between governmental departments of health and education. ${ }^{125}$ In sum, while there has been increased political will to respond to the need for more effective sexual and reproductive education, there is too great a variation in terms of the content, methods of delivery and quality of teaching. An issue that is considered within the review and that is the subject of future research, is how prevalent the interference by groups with cultural or religious agendas is concerning sexual and reproductive health education - specifically concerning the female reproductive life cycle.

The sexual and reproductive wellness industry would lose much of its power if young people had access via their primary and secondary school curricula to evidence-based

art 12; European Convention for the Protection of Human Rights and Fundamental Freedoms, as amended by Protocols Nos. 11 and 14 and supplemented by Protocols Nos. 1, 4, 6, 7 12, 13 and 16, Council of Europe Treaty Series No. 5 (adopted on 4 November 1950, entered into force on 3 September 1953), art 2.

115 Convention on the Elimination of All Forms of Discrimination Against Women, note 107, art 10.

${ }^{116}$ UN Committee on the Elimination of All Forms of Discrimination Against Women, 'General Comment No. 36 on Girls' and Women's Right to Education' CEDAW/C/GC/36 (16 November 2017), para 9.

117 Committee on Economic, Social and Cultural Rights, note 108, para 7.

118 Ibid, para 15.

119 Ibid, para 18.

120 Ibid, para 21.

121 See, e.g., Block, note 31; Nabel, note 32; Dusenbery, note 32; and Villarosa, note 32.

${ }^{122}$ Leung et al, note 41.

${ }^{123}$ UNESCO, 'Comprehensive Sexuality Education: A Global Review’ (2015), https://unesdoc.unesco.org/ark:/ 48223/pf0000235707 (accessed 19 October 2021) 3.

${ }^{124}$ Ibid, 4.

125 Ibid. 
learning about puberty, fertility (and the issues surrounding it, including infertility), what happens to the body when an individual becomes pregnant, delivers a baby, has a miscarriage/abortion, or transitions to another sex, and the slow cessation to the end of the menstrual life cycle beginning with perimenopause and ending with the menopause, inclusive of the myriad of experiences which accompany these stages. Women and girls would be less vulnerable to industry marketing around sexual and reproductive wellness if the same empowering curriculum was taught to everyone.

In Part II of this article we demonstrated that the industry is dangerously unregulated or under-regulated in various jurisdictions, with legal cases being brought concerning unsubstantiated claims and possible harms to sexual and reproductive health. Furthermore, the industry is rife with misinformation. In this section, we have demonstrated that there is a human right to access to sexual and reproductive health care and education without discrimination that states have positive obligations to respect, protect and fulfil. In the following concluding parts of the paper, we will make the case for including the industry in the BHR agenda.

\section{Application of the Business and Human Rights Framework to Sexual and Reproductive Health and Education Rights}

This article forms part of a larger scoping project undertaken by the author team to determine the future research agenda to address the harms caused to women and girls by the marketing of products that interfere with sexual and reproductive healthcare and education. As part of this, we considered various fields that intersect with business, law and ethics as the optimal paradigm within which to frame and ultimately examine the issue. This was narrowed to the field of BHR.

BHR was born of the desire to hold businesses accountable for both individual and collective harmful effects to people and to prevent or mitigate such harms by building a framework of expectations that are grounded in a specific core set of human rights obligations. ${ }^{126}$ The development of the BHR scholarship included the need to elevate the responsibility and role of non-state actors to work along with states to protect the rights embodied in human rights treaties. BHR is the appropriate framework, therefore, to use when the rights of a person, or group of people, are being harmed.

In 2019, the United Nations Working Group on BHR (UNWG) adopted a report on the 'gender dimension' of the United Nations Guiding Principles on Business and Human Rights (UNGPs). ${ }^{127}$ This report highlights shortcomings vis-à-vis gender in current state and business measures to implement the UNGPs ${ }^{128}$ and identifies concrete measures that might be taken by both states and businesses in discharging their respective responsibilities under the UNGPs relating to gender equality. ${ }^{129}$

As outlined above, the sexual and reproductive wellness industry is highly gendered, selling products almost exclusively to women and girls that directly impact their sexual and reproductive health. Business enterprises in this industry have capitalized on the neoliberal

\footnotetext{
${ }^{126}$ Human Rights Council, 'Protect, Respect and Remedy: A Framework for Business and Human Rights', A/HRC/8/5 (7 April 2008).

${ }^{127}$ Human Rights Council, 'Gender Dimensions of the Guiding Principles on Business and Human Rights: Report of the Working Group on the Issue of Human Rights and Transnational Corporations and Other Business Enterprises', A/HRC/41/43 (23 May 2019) (Gender Guidance).

${ }^{128}$ Human Rights Council, 'Guiding Principles on Business and Human Rights: Implementing the United Nations “Protect, Respect and Remedy” Framework', A/HRC/17/31 (21 March 2011) (UNGPs).

${ }^{129}$ Gender Guidance, note 127, 2.
} 
approaches to healthcare and education gaps that exist in many countries resulting in the commodification of the female reproductive life cycle. These harmful marketing practices are addressed by the UNWG, which notes that: 'Business enterprises should not perpetuate gender stereotypes or objectify and sexualize women's bodies in any process, including sales and marketing, related to their products or services' (emphasis added). ${ }^{130}$

'Sales and marketing' is thus clearly identified as a gendered human rights issue. Furthermore, UNGP 13 states that the business responsibility to respect human rights involves avoiding adverse human rights impacts, addressing these if they occur, and preventing or mitigating abuses 'directly linked to their operations'. ${ }^{131}$ These responsibilities are currently being ignored by the industry which must be integrated within the BHR agenda to ensure that states, businesses and rights-holders are aware of SRHR and that these rights are respected, protected, and if abused, access to remedy is provided.

This article has described three examples of how the industry has created, and profited from, stereotypes about the bodies of women and girls. It must be noted, however, that there are many other instances where business enterprises across a range of retail fields target female bodies with products that are unnecessary and harmful and where long-term impacts are unknown. The UNWG draws attention to these forms of sales and marketing as a BHR issue of importance when applying the UNGPs through a gender lens. The predatory marketing of unnecessary or harmful products by business enterprises must be further examined to better understand why so many products and marketing strategies go unregulated and how this can be addressed at both the international and domestic levels. The future research agenda should consider the best approaches for the effective regulation of businesses operating in the sphere of sexual and reproductive health, for example, domestic consumer protection laws could be useful vehicles of response to regulating the industry at the domestic level.

\section{Conclusion}

In this article, we have established that harmful marketing or unnecessary products aimed at the female reproductive cycle is a BHR issue but also that there is much work still to be done. By applying a gender analysis to the sexual and reproductive wellness industry, we have demonstrated that states and businesses are failing in their responsibilities to women and girls concerning the protection of their rights to sexual and reproductive health. Coupled with deficient education about sexual and reproductive health, business enterprises are profiting, often in predatory and harmful ways.

To contextualize these issues within BHR, we have demonstrated that a growing sexual and reproductive wellness industry exists; products sold within this industry overwhelmingly target women and girls who are aged within the female fertility life cycle years; these products are largely unregulated both in labelling (claims made) and in how they are marketed (including increasing problems with online advertising); the international human rights framework is unequivocal that sexual and reproductive healthcare and education are human rights that should be protected without discrimination; and the BHR framework places responsibility on both states and businesses to respect and protect human rights. Consequently, businesses have responsibilities to respect such human rights, and states have a protective duty to regulate the industry in domestic legislation to ensure that sexual and reproductive rights are not being abused and if they are, access to remedy must be provided.

\footnotetext{
130 Ibid, 18.

${ }^{131}$ UNGPs, note 128, principle 13.
} 
Upon this basis, we suggest that the future BHR research agenda includes: (1) further study on the advertising and marketing practices of all industries selling and marketing products that are highly gendered (for example, cosmetics or dietary supplements), and this research should foreground social media and online practices; (2) research on the laws concerning the packaging and labelling of products within the industry; (3) study into the effects on women and girls of the marketing of products that fall under the definition of the industry; (4) a review of extant research on advertising as a source of information in a public health context, situated within a review of World Trade Organisation rules; ${ }^{132}$ (5) research into best practice for embedding into domestic law the guidance provided by the UNWG relating to gender and marketing to assist states to develop effective regulatory tools; and (6) scholars are encouraged to research cultural influences on sexual and reproductive healthcare and education across the areas identified in this article and beyond as necessary.

We hope that fellow BHR scholars will join the conversation and collaborate to use the tools of law, corporate governance and the weight of public consciousness to assist us in moving the regulation of the sexual and reproductive wellness industry to the fore of the BHR agenda.

Conflicts of interest. The authors declare none.

Funding. The authors received no funding for the research of this work.

\footnotetext{
${ }^{132}$ See, e.g., Amandine Garde, 'Harmful Commercial Marketing and Children's Rights: For a Better Use of EU Powers' (2020) 11:4 European Journal of Risk Regulation 841; Philip Nelson, 'Advertising as Information' (1974) 82:4 Journal of Political Economy 729; Henry Saffer and Frank Chaloupka 'The Effect of Tobacco Advertising on Tobacco Consumption' (2000) 19:6 Journal of Health Economics 1117.
} 